\title{
Innovative Medicines Initiative plays the long game on research funding
}

To the Editor - I read the Letter 'Research funding after COVID-19', in which Miguel Prudêncio \& Joana C. Costa questioned the impact of reactive, short-term funding responses to health emergencies such as COVID-19 (ref. ${ }^{1}$ ). As an example, they cited the Ebola projects of the Innovative Medicines Initiative (IMI) and stated that 'no drugs or licensed vaccines are available to treat or prevent [...] Ebola'.

On the suggestion that our Ebola programme is 'short term', I would like to highlight the investment made by the IMI of close to $€ 300$ million in 12 Ebola projects, half of which have a duration of 5-7 years. The last projects will finish in 2023.

On the availability of a vaccine, European and United States regulators approved the rVSV-ZEBOV Ebola vaccine at the end of 2019 (refs. ${ }^{2,3}$ ), and the European Commission approved the Janssen Ebola vaccine regimen on 1 July 2020 (ref. ${ }^{2}$ ). IMI, along with other organizations including Bavarian Nordic A/S, the Biomedical Advanced Research and Development Authority, and the National Institutes of Health, significantly supported the development of the Janssen vaccine. IMI's contributions included support for clinical trials in Europe and Africa, as well as support for vaccine manufacture and for compliance and capacity building in Africa to ensure that clinical trials could take place. IMI projects also supported the development of the rVSV-ZEBOV vaccine by analysing and characterizing the immune response to the vaccine. IMI projects have delivered tools to support the engagement of local communities in clinical trials, such as A Guidebook on Community Engagement, Communications, and Technology for Clinical Trials in Outbreak Settings ${ }^{4}$, which could also be utilized for other disease areas. Finally, IMI has funded projects to develop rapid diagnostic tests which has resulted in a commercially available, CE-marked, in vitro diagnostic mobile detection platform that can detect whether an individual has Ebola (or a related disease such as Marburg virus) within 75 minutes. It can be used with only limited training and is designed to work in sites where high-end laboratory infrastructures are not available . $^{5}$

IMI's Ebola projects were launched extremely rapidly, and this experience helped us to quickly launch projects to develop treatments and rapid diagnostic tests for COVID-19. A call for proposals launched on 3 March 2020 resulted in eight projects (three on treatments and five on diagnostics), with a total budget of $€ 116$ million coming from the European Union's Horizon 2020 programme, pharmaceutical companies' in-kind donations and other contributions ${ }^{6}$. As with our Ebola projects, this is no short-term investment - our portfolio includes projects with durations of 4-5 years, and while the focus is obviously on the current COVID-19 outbreak, a number of the projects' results will also be relevant for future outbreaks caused by other coronaviruses.

More broadly, some of IMI's other projects have applied their knowledge, skills and resources to tackling the COVID-19 outbreak. For example, IMI's EHDEN and ConcePTION projects and the ADVANCE/ VAC4EU initiative will help the European Medicines Agency gather real-world data on COVID-19 vaccines and treatments once they are approved and used in day-to-day clinical practice?.

Elsewhere, IMI's COMBACTE projects have created a pan-European network of 975 hospitals and 800 laboratories for clinical studies and trials on antimicrobial resistance. Scientists are now turning to the networks to identify sites for clinical trials of potential COVID-19 treatments.

In conclusion, I agree that research funders have a responsibility to fund projects that will have an impact on health. However, it is incorrect to suggest that the funds made available by IMI (and others) in the wake of the West African Ebola outbreak have not made a difference. Thanks to the long-term investments of a wide range of funders, the world is now much better placed to prevent and deal with an Ebola outbreak. Moreover, the experience of responding to the Ebola outbreak has helped to shape our response to the current coronavirus pandemic.

\section{Pierre Meulien $\bowtie$}

Innovative Medicines Initiative (IMI),

Brussels, Belgium.

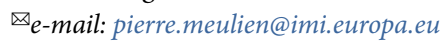

Published online: 28 January 2021

https://doi.org/10.1038/s41564-020-00862-Z

References

1. Prudêncio, M. \& Costa, J. C. Nat. Microbiol. 5, 986 (2020).

2. Vaccine against Ebola: Commission grants first-ever market authorisation. European Commission http://go.nature. com/3ngeaf7 (2019).

3. First FDA-approved vaccine for the prevention of Ebola virus disease, marking a critical milestone in public health preparedness and response. United States Food and Drug Administration http://go.nature.com/3hSjeW0 (2019).

4. Smout, B., Schulz, W., Larson, H., Willems, A. \& Mc Kenna, P. A Guidebook on Community Engagement, Communications, and Technology for Clinical Trials in Outbreak Settings (EBODAC, 2018).

5. Mofina factsheet. Innovative Medicines Initiative http://go.nature. com/3ohSFfc (accessed 17 December 2020).

6. IMI2 - Call 21. Innovative Medicines Initiative http://go.nature com/3niUtmG (accessed 17 December 2020).

7. COVID-19: EMA sets up infrastructure for real-world monitoring of treatments and vaccines. European Medicines Agency http://go.nature.com/3pR2m4K (2020).

8. Continuing the fight: COVID-19. COMBACTE http://go.nature. com/2LowUM0 (2020).

Competing interests

P.M. is the Executive Director of the IMI, which is supported by the European Union's Horizon 2020 Research and Innovation programme and the European Federation of Pharmaceutical Industries and Associations (EFPIA). The opinions expressed in this article do not necessarily reflect the positions and opinions of the European Commission or EFPIA. 